\title{
SISTEM INFORMASI AKUNTANSI PERSEDIAAN BARANG BERBASIS KOMPUTER PADA BAGIAN GUDANG DI SEKOLAH CINTA KASIH JAKARTA
}

\author{
Saut Aleksius Siregar \\ Program Studi Sistem Informasi, STMIK Widuri Jakarta \\ E-mail: alekzuchi@yahoo.com
}

Submission date: 2020-02-26

Accepted date: $2020-03-25$

\begin{abstract}
Technology development has a very important role in information management. Processing information related to large and fast inventory flows in a company certainly requires accuracy, efficiency, and effectiveness of information systems. This problem is experienced by the Sekolah Cinta Kasih in the activities of those who still use the manual recording system. The type of research used is descriptive research with a case study approach. By doing a series of system analysis, the author intends to design a computerized inventory information system. The system uses Microsoft Access 2010 which is capable of being operated in a Microsoft Windows XP operating system or a higher version of Windows.The computerized information system is expected to provide various facilities for the warehouse in processing database information and reports that are accurate, fast, and efficient. And minimize errors in inventory control. The new system design aims to prevent errors in the Accounting Information System Inventory by the Sekolah Cinta Kasih. The results obtained indicate that the use of accounting information systems at school shows the results that can be expected to be used. In addition to all the use of accounting information systems can be applied properly and produce significant results.
\end{abstract}

Keywords: Designing, Information Systems, Inventory, Schools

\begin{abstract}
ABSTRAK
Perkembangan teknologi memiliki peranan yang sangat penting dalam manajemen informasi. Pengolahan informasi terkait dengan arus persediaan yang besar dan cepat dalam sebuah perusahaan tentunya membutuhkan akurasi, efisiensi, dan efektifitas sistem informasi. Permasalahan inilah yang dialami oleh Sekolah Cinta Kasih dalam aktivitas mereka yang masih menggunakan sistem pencatatan manual. Jenis penelitian yang digunakan adalah penelitian deskriptif dengan pendekatan studi kasus. Dengan dilakukannya serangkaian analisa sistem, penulis bermaksud merancang suatu sistem informasi persediaan yang terkomputerisasi. Sistem tersebut menggunakan Microsoft Access 2010 yang mampu dioperasikan dalam sistem operasi Microsoft Windows XP atau versi Windows yang lebih tinggi. Sistem informasi terkomputerisasi tersebut diharapkan mampu memberikan berbagai kemudahan bagi pihak gudang dalam mengolah informasi database dan laporan yang akurat, cepat, dan efisien. Serta meminimalkan kesalahan dalam pengendalian persediaan di Sekolah Cinta Kasih. Hasil diperoleh menunjukkan bahwa penggunaan sistem informasi akuntansi disekolah menujukkan hasil yang bisa diharapkan penggunaannya. Selain itu untuk semua penggunaan sistem informasi akuntasi dapat diterapkan dengan baik dan menghasilkan hasil yang signifikan.
\end{abstract}

Kata Kunci: Perancangan, Sistem Informasi, Persediaan, Access

\section{PENDAHULUAN}

Perkembangan teknologi informasi yang sangat pesat mempunyai dampak dalam peningkatan efektifitas dan keefisienan dalam melakukan setiap pekerjaan. Pengelolaan yang baik dan dengan dukungan pihak manajemen yang handal tentunya sangat diperlukan untuk menghadapi perkembangan dunia usaha yang terus berjalan. Dalam mengambil kebijakan, pimpinan harus memperhatikan informasi-informasi mengenai kondisi dan permasalahan yang dihadapi organisasi atau perusahaan sehingga dapat dilaksanakan oleh para karyawan dengan hasil yang memuaskan. Informasi- informasi tersebut dapat diperoleh dari sistem yang telah diterapkan perusahaan (Davis \& Yen, 1998; Hussain \& Raghavan, 2017).

Sekolah Cinta Kasih dengan jumlah siswa sebesar 2038 siswa Tahun pelajaran 2018/2019 yang terdiri dari jenjang pendidikan KB, TK, SD, SMP, SMK dan SMA. Agar terselenggaranya pendidikan yang baik maka manajemen mengadakan persediaan untuk barangbarang yang digunakan rutin setiap hari untuk menunjang pembelajaran seperti, seragam dan perlengkapan siswa lainnya. Untuk itu diperlukan Aplikasi Akuntnasi Persediaan Barang Berbasis Komputer. 
Sistem pada dasarnya adalah sekelompok unsur yang erat berhubungan satu dengan lainnya, yang berfungsi bersama-sama untuk mencapai tujuan tertentu (Agrianto, 2014). Pengertian lainnya sistem adalah rangkaian dari dua atau lebih komponen yang saling berhubungan yang berinteraksi untuk mencapai suatu tujuan. Sistem hampir selalu terdiri dari beberapa subsistem kecil yang masing-masing melakukan fungsi khusus yang penting untuk dan mendukung bagi sistem yang lebih besar tempat mereka berada (McLeod \& Schell, 2004; Wisna, 2013).

Sistem informasi dapat diartikan sebagai sistem yang menghasilkan output berupa informasi yang berguna bagi tingkatan manajemen. Menurut (Jogiyanto, 2005) dalam bukunya yang berjudul analisis dan desain mengemukakan definisi sistem informasi adalah suatu sistem di dalam suatu organisasi yang mempertemukan kebutuhan pengolahan transaksi harian, mendukung operasi, bersifat manajerial dan kegiatan strategi suatu organisasi dan menyediakan pihak luar tertentu dengan laporan - laporan yang diperlukan

Sistem Informasi Akuntansi adalah sebuah sistem yang memproses data dan transaksi guna menghasilkan informasi yang bermanfaat untuk merencanakan, mengendalikan dan mengoperasikan bisnis (Bodnar \& Hopwood, 2006; Kurniawan \& Khairani, 2014)

Menurut Mulyadi dalam bukunya yang berjudul Sistem Akuntansi metode pencatatan persediaan dibedakan menjadi dua yaitu : (1) Metode Mutasi Persediaan (Perpectual inventory Method):Setiap mutasi persediaan dicatat dalam kartu persediaan. (2) Metode Persediaan Fisik (Physical Inventory Method) :Hanya tambahan persediaan dari pembelian saja yang dicatat (Agrianto, 2014; Kurniawan \& Khairani, 2014)

\section{METODE PENELITIAN}

Mengadakan penelitian secara langsung terhadap objek yang akan diteliti, dan dari sumber-sumber primer dan sekunder yang mendukung penelitian ini seperti, artikelartikel dari internet, mengambil referensi dari buku-buku yang berhubungan dengan materi (Sani, Subiyakto, \& Rahman, 2018).

\section{Metode Pengembangan Sistem}

a. Desain sistem bertujuan untuk memberikan gambaran umum kepada user tentang sistem yang baru yang akan dikembangkan yaitu sistem informasi akuntansi persediaan. b. Desain Interface merupakan perancangan bentuk interface program yang dibuat, dengan tujuan supaya pemakai mudah mengerti.

c. Desain database merupakan suatu komponen yang terpenting dalam penyusunan aplikasi komputer. Tabel pada database yang diperlukan antara lain: tabel Persediaan sergam, tabel supplier, dan tabel pengeluaran.

d. Desain Teknologi dirancang guna menentukan kebutuhan hardware dan software yang akan digunakan dan melaksanakan sistem yang mempunyai fungsi sebagai penerima masukan, menjalankan program, menyimpan data dan menghasilkan keluaran (Weaver, Jansen, Van Grootveld, Van Spiegel, \& Vergragt, 2017).

e. Implementasi sistem yang sudah siap akan dilakukan pada tahap ini, dengan kriteria program dan penggunaan yang mudah dipahami oleh bagian gudang.

\section{HASIL DAN PEMBAHASAN}

\section{Uraian Prosedur Pengeluaran Barang Sistem Persediaan}

a. Bagian Gudang menerima Nota sebanyak 1 lembar dari bagian Penjualan yang berisi daftar seragam yang diminta oleh pelanggan.

b. Selanjutnya bagian Gudang akan memeriksa ketersediaan seragam yang diminta pelanggan mengenai stok seragam lalu mengecek jumlah seragam yang diminta secara fisik.

c. Jika seragam yang diminta masih tersedia, bagian Gudang akan menyiapkan seragam - seragam tersebut untuk dikirim dan memberikan kembali Nota yang telah dicek ketersediaannya kepada bagian penjualan untuk dibuatkan Nota Penjualan.

d. Selanjutnya bagian Admin Gudang menerima copy Nota Penjualan rangkap ke-3 dari Bagian Penjualan sebanyak 1 lembar sebagai dokumen yang akan digunakan untuk memperbaharui jumlah persediaan.

e. Kemudian Admin Gudang mencatat ke komputer data yang ada pada Nota Penjualan untuk memperbarui jumlah persediaan.

f. Admin Gudang kemudian mengarsipkan Nota Penjualan tersebut berdasarkan No urut Nota Penjualan.

g. Tetapi apabila seragam - seragam yang diminta tidak tersedia di gudang, Nota akan dikembalikan ke Bagian Penjualan untuk ditindaklanjuti. 


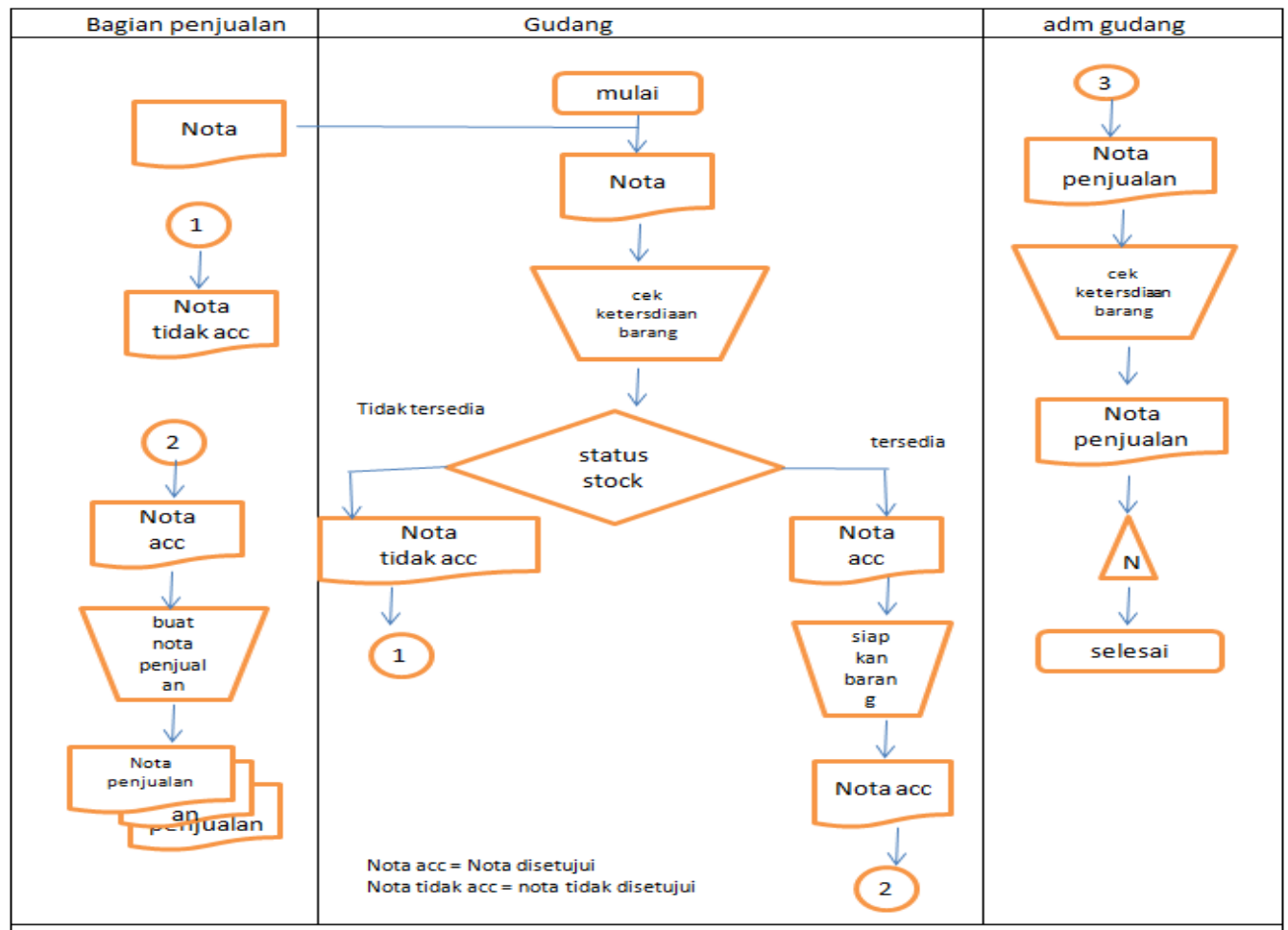

Sumber: (Alexius, 2019)

Gambar 1. Flow Chart Sistem Persediaan Berjalan Prosedur Pengeluaran Barang

\section{Perancangan Sistem dan Implementasi Sistem}

1. Bagian Gudang menerima Nota $(\mathrm{N})$ sebanyak 1 lembar dari bagian Penjualan yang berisi daftar seragam siswa yang diminta oleh pelanggan.

2. Bagian Gudang memeriksa ketersediaan seragam kepada admin gudang mengenai stok seragam menurut database barang.

3. Apabila seragam siswa yang diminta tersedia, bagian Gudang akan menyiapkan seragam - seragam tersebut untuk dikirim dan mencatatnya kedalam kartu gudang, dan memberikan Nota yang telah dicek ketersediaan seragam tersebut $(\mathrm{N})$ kepada Admin Gudang untuk dibuatkan Bukti Pengeluaran Barang Gudang.

4. Bagian Admin Gudang mengelola data pengeluaran, seperti menginput data Nota (beserta jumlah barang yang telah dikeluarkan oleh bagian Gudang) ke dalam form input Bukti Pengeluaran Barang Gudang (BPBG) dan menyimpannya ke database BPBG untuk mengupdate jumlah persediaan barang pada database Barang.
5. Dari display BPBG yang telah diisi tadi, Admin Gudang mencetak Bukti Pengeluaran Barang Gudang (BPBG) sebanyak 1 lembar dan menyerahkannya ke Gudang bersama dengan Nota yang telah disetujui (Nota ACC).

6. Bagian Gudang memeriksa BPGB yang dibuat oleh Admin Gudang dengan Nota, dan menandatanganinya sebagai tanda bahwa BPBG telah sesuai dan disetujui (BPBG). Bagian Gudang menyerahkan kedua BPBG yang telah ditandatangani ke Bagian Penjualan untuk dibuatkan Nota Penjualan sedangkan Nota dikembalikan ke Admin Gudang untuk diarsip.

7. Bagian Admin Gudang menerima copy Nota Penjualan dari Bagian Penjualan kemudian mencocokannya dengan Nota serta mengarsipkannya.

8. Apabila seragam-sergam siswa yang diminta tidak tersedia di gudang, Nota akan dikembalikan ke bagian penjualan untuk ditindaklanjuti. 


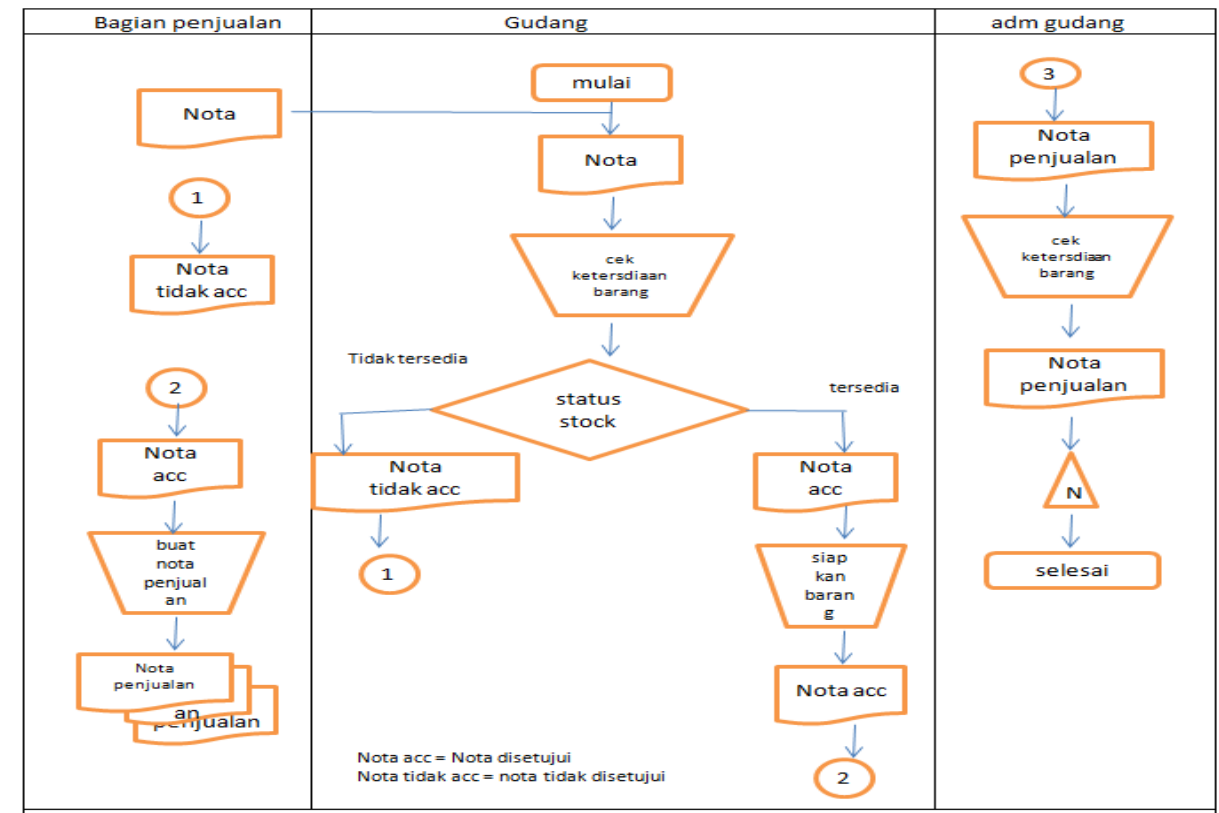

Sumber: (Alexius, 2019)

Gambar 2. Flow Chart Sistem Persediaan Usulam Prosedur Pengeluaran Barang

\section{Usulan Rancangan Dialog Screen}

Nama dialog : Input Master Persediaan Seragam

Fungsi : untuk menginput data Persediaan Seragam

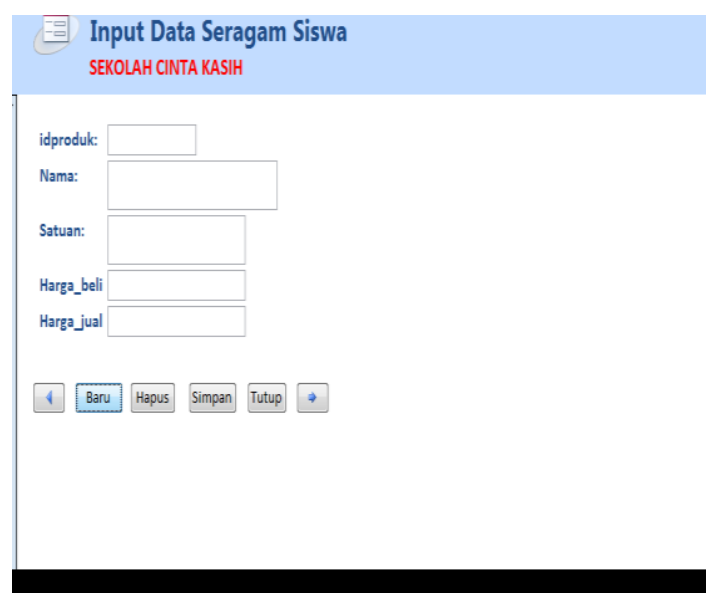

Sumber: (Alexius, 2019)

Gambar 3. Input Data Persediaan seragam
Dialog Screen : Bukti Pengeluaran Barang Fungsi Mencatat Barang yang telah dikeluarkan oleh bagian gudang

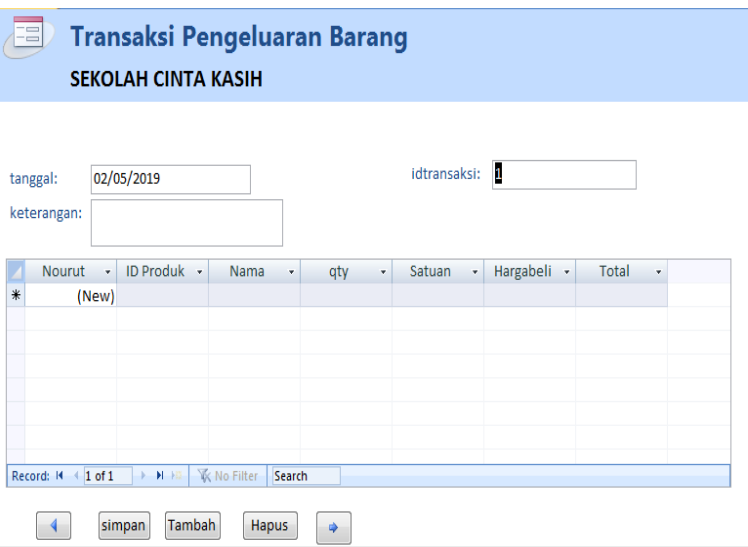

Sumber: (Alexius, 2019)

Gambar 4. Bukti Pengeluaran Barang

Dialog Screen : Cari BPBG

Fungsi : Untuk mencari data BPBGDialog Screen : Laporan Inventory Gudang

Fungsi : Untuk menampilkan data akhir gudang setiap akhir bulan 


\section{SEROLAH CINTA KASIII}

\section{LAPORAN INVENTORY GUDANG}

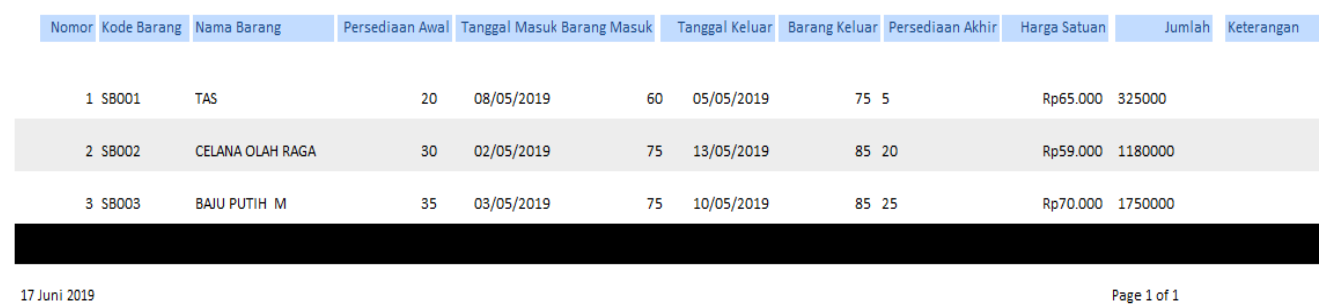

Sumber: (Alexius, 2019)

Gambar 5. Screen laporan inventory persediaan seragam

\section{KESIMPULAN}

Berdasarkan hasil penelitian yang dilakukan oleh penulis maka penulis memberikan kesimpulan sebagai berikut :

1. Sistem informasi Akuntansi Persediaan seragam telah layak digunakan untuk menggantikan proses pelayanan manual yang berjalan pada Sekolah Cinta Kasih Jakarta.

2. Perancangan Sistem informasi Akuntansi Persediaan akan membantu manajemen untuk memperoleh informasi dengan efektif serta efisien

3. Perancangan Sistem informasi Akuntansi Persediaan akan membantu manajemen untuk memperoleh informasi dengan efektif serta efisien.

4. Sistem informasi Akuntansi Persediaan yang telah dirancang menghasilkan data akurat karena diolah secara komputerisasi,

\section{DAFTAR PUSTAKA}

Agrianto, R. S. (2014). Analisis Sistem Akuntansi Penggajian Dan Pengupahan Dalam Upaya Meningkatkan Efektivitas Pengendalian Internal Perusahaan (Studikasuspada PT. Duta Paper Prigen Pasuruan). Jurnal Administrasi Bisnis, 7(1).

Bodnar, G. H., \& Hopwood, W. S. (2006). Sistem informasi akuntansi. Jakarta: Salemba Empat.
Davis, W. S., \& Yen, D. C. (1998). The Information System Consultant's Handbook: Systems Analysis and Design: CRC press.

Hussain, M. F. B. M., \& Raghavan, S. (2017). Interrelationships among Information System Quality, Intention to Use, Perceived Usefulness, Technology Readiness and their Effect on E-Commerce Adoption among SMEs. ANVESHAK-International Journal of Management, 6(1), 122-137.

Jogiyanto, H. (2005). Analisis dan Desain Sistem Informasi Yogyakarta: Andi Offset.

Kurniawan, I. N., \& Khairani, S. (2014). Analisis Sistem Informasi Akuntansi Atas Pembelian dan Pengeluaran Kas Pada PT XYZ.

McLeod, R., \& Schell, G. (2004). Sistem informasi manajemen: Indeks.

Sani, A., Subiyakto, A., \& Rahman, T. K. A. (2018). Integration of the Technology Readiness and Adoption Models for Assessing IT Use among SMEs in Indonesia.

Weaver, P., Jansen, L., Van Grootveld, G., Van Spiegel, E., \& Vergragt, P. (2017). Sustainable technology development: Routledge.

Wisna, N. (2013). The Effect of Information Technology on the Quality of Accounting Information system and its impact on the Quality of Accounting Information. Research Journal of Finance and Accounting, 4(15), 2222-2847. 
